DOI: 10.17234/SRAZ.65.38

UDK: 821.135.1.09 Mihali, F.

\title{
Țara brînzei - proza confesională a Feliciei Mihali
}

\author{
Ivana Olujić \\ Manuela Džankić \\ Universitatea din Zagreb, Facultatea de Științe Umaniste și Sociale \\ iolujic@ffzg.hr \\ manueladzankic@gmail.com
}

\begin{abstract}
Punctul central al cercetării noastre este romanul Țara brînzei (1999) de Felicia Mihali, o scriitoare contemporană de origine română. În anul 2000 autoarea a emigrat în Canada și s-a stabilit în orașul Montreal, unde a tradus ea însăși romanul în franceză, publicându-1 sub titlul Le pays du fromage în 2002. Țara brînzei este romanul cu care a debutat și care s-a bucurat de o bună receptare în ambele țări. Abordăm subiectul acestui roman ca pe un discurs confesional, apropiat de un jurnal intim.
\end{abstract}

Cuvinte cheie: Felicia Mihali, literatura română, autotraducere, intertextualitate

\section{Introducere}

Panaït Istrati, Tristan Tzara, Eugène Ionesco, Emil Cioran sunt unii dintre cei mai cunoscuți scriitori francofoni de origine română. Lista este, totuși, mai lungă și încă deschisă. Ne-am propus ca în această lucrare să ne ocupăm de începuturile literare ale unei scriitoare române care a plecat din România la începutul anilor 2000 pentru a se stabili în Canada, integrându-se apoi în literatura quebecoeză, la început cea francofonă, iar pe urmă și în cea anglofonă.

Felicia Mihali s-a născut în România în anul 1967. A absolvit secția de românăfranceză la Facultatea de Litere și pe cea de chineză-olandeză la Facultatea de Limbi și Literaturi Străine, Universitatea din București. În momentul plecării definitive din țară avea deja trei romane publicate în limba română: Țara brînzei (1999), Mica istorie (1999) și Eu, Luca și chinezul (1999). Două dintre ele au fost traduse ulterior în franceză de către autoarea însăși: Le pays du fromage (2002)

1 Comunicarea prezentată în cadrul simpozionului 100 de ani de romanistică la Zagreb: tradiție, contacte, perspective a inclus și partea legată de autotraducerea romanului Țara brînzei, care va fi prezentată într-un articol separat. 
și Luc, le Chinois et moi (2004), iar după aceste două traduceri autoarea a început să scrie direct în franceză, apoi și în engleză, publicând: La reine et le soldat (2005), Sweet, sweet China (2007), Dina (2008), Confession pour un ordinateur (2009), L'enlèvement de Sabina (2011) la renumita editură XYZ Editeur, dar și The Darling of Kandahar (2012) și A Second Chance (2014) la editura Linda Leith Publishing. Emisiunea Canada Reads a nominalizat romanul The Darling of Kandahar în topul celor mai bune zece cărți ale anului 2013 în Quebec (Iliceanu: 2015).

\section{2. Țara brînzei}

Romanul Țara brînzei a apărut în România în 1999, deci, într-un moment editorial neoportun (Chișu 2016; Manolescu 2008: 1398). Totuși, s-a bucurat de o bună receptare și în România, ca și în Canada în 2002. Tanguay (2002) scrie că acest roman este „o excelentă primă lucrare a Feliciei Mihali, o tânără scriitoare de origine română, care a ales să rescrie în franceză povestea sa marcată de figurile naufragiului și disperării”, iar Chartrand (2002) îi mulțumește autoarei „pentru că a avut ideea de a se stabili aici acum doi ani, după ce a părăsit România natală: ea ne oferă, ca un cadou neașteptat, acest prim roman care dezvăluie deja un talent scriitoricesc".

\subsection{Discursul confesional al unui personaj exilat}

Acțiunea romanului este relativ simplă: o femeie tânără (naratoarea, fără nume), aflând că soțul o înșală, pleacă împreună cu fiul său în vârstă de patru ani într-un sat situat „undeva între Roșiori de Vede și Drăgănești” (ȚB: 15), la casa părinților, care muriseră de câțiva ani. Satul unde a crescut este în prezent izolat și pustiu, aproape fără oameni, infestat de purici, numai cu un magazin și o poștă cu un telefon. Casa părintească în care se mută este aproape o ruină. Ea petrece următoarele 18 luni în acest loc unde nu se întâmplă nimic. În acest timp alternează perioade de activitate extremă, de curățenie și reorganizare, cu perioade de pasivitate completă. Fazele pasive devin, totuși, din ce în ce mai lungi, mai ales după ce soțul ei îl ia pe fiul lor, ea nemaifiind în stare să aibă grijă de el. Acest fapt o lasă emoțional rece. Intră în două relații mai degrabă sexuale decât de dragoste, care duc la două sarcini, terminate cu avorturi - iarăși, este afectată mai mult fizic. Trăiește din ce în ce mai des într-o lume a fanteziilor. Finalul aduce o schimbare doar aparentă - după prăbușirea casei, tânăra femeie se află din nou în situația de la început: soțul ei îi promite întoarcerea la viața în familie, într-un apartament mai mare și cu o slujbă permanentă, ceea ce înseamnă de fapt la închisoarea vieții sale anterioare, cunoscute și monotone.

Sunt mai multe argumente pentru citirea romanului (și) în cheie psihanalitică: întoarcerea în satul natal și confruntarea neplăcută cu copilăria, tonul confesional și introspecția cu care este întrepătrunsă narațiunea (care formal imită un jurnal, cu un capitol pentru fiecare lună), lungile episoade de reverii (asemănătoare visurilor). $\mathrm{Nu}$ se poate scăpa din vedere nici faptul că se pune sub semnul 
întrebării abilitatea naratoarei de a iubi și de a lucra - două condiții ale maturității din perspectiva psihanalizei.

În acest sens, devine repede evident că motivul său interior pentru părăsirea Bucureștiului este mai complex decât cel declarat la început: după ce a fost dată afară de la serviciu a trăit într-o rutină obositoare, iar excesul de timp liber a scos în evidență criza interioară. Uitându-se dimineți în șir de pe balconul său la un bătrân care își face micile ritualuri zilnice, se trezește în naratoarea o revoltă și o dorință de schimbare și explorare, care începe cu întoarcerea „,acasă”. Dar această lungă expediție de schimbare (a soartei, dar și a personalității), împreună cu confesiunea (terapeutică?) nu dă aproape niciun rezultat: spre sfârșitul romanului naratoarea pendulează între trecut și prezent jucându-se cu timpul, alternând episoadele actuale și cele din copilărie cu fantezii despre războiul din Troia și străbunicii săi, povestiri cu care se identifică, devenind complet detașată de realitate și preferând să trăiască doar în lumea fanteziilor: „Nu mai știam cînd începe ziua și cînd se sfîrșește noaptea”, „,Nu vroiam să mă trezesc niciodată, să scap de prigoana la care eram supusă" (ȚB: 97, 110). Pare că va accepta mutarea cu amantul la Craiova din pură inerție, dar în ajunul plecării casa părintească se prăbușește peste ea și ea rămâne sub ruine câteva zile înainte a fi găsită și dusă la spital. Simbolic, este aproape omorâtă de amintirile sale: se prăbușesc în același timp casa, viața și istoria întreagă, iar ea este distrusă și complet înstrăinată de lume, însă în același timp complet lucidă.

Așa revine la început, fără vreo revelație cathartică, iar singura concluzie a aventurii sale o citim în epilog: „La treizeci de ani, făcusem prima și probabil ultima încercare conștientă de schimbare. Eșuasem. (...) Dacă aflasem ceva despre mine, la ce bun? Mă umplusem inutil de tristețe, pentru că orice demers în calea prăbușirii noastre era zadarnic. Ca și ceilalți, nu eram dispusă să învăț. Orice experiență mă lăsa în cele din urmă rece, iar lumea mă va obliga să fiu cu adevărat proastă. De acum nimic nu-mi va opri căderea." (ȚB: 216).

\subsection{Robinsoniada}

Motivul aventurii este subliniat prin faptul că personajul ia cu sine în autoexilul său (ȚB: 196) numai două cărți, romanele Robinson Crusoe de Daniel Defoe și Vineri sau limburile Pacificului de Michel Tournier, lucru remarcat imediat de criticii canadieni (Chartrand: 2002, Thibeault: 2002).

In ambele romane menționate puterile personajelor sunt testate printr-o serie de provocări, o aventură neașteptată fiind începutul și mijlocul căutării lor de sine. În linii esențiale, Robinson Crusoe (1719) este o autobiografie ficțională în care personajul principal petrece 28 de ani pe o insulă pustie înainte de a fi salvat, iar în romanul lui Tournier (din 1967) același personaj este din nou plasat pe o insulă pustie, dar cu sfârșit diferit: personajul nu mai vrea să revină acasă, fiindcă s-a schimbat prea mult în timpul șederii sale pe insulă și se simte om mai mult acolo decât în lumea civilizată. Prin acest element de intertextualitate Felicia Mihali indică faptul că naratoarea este conștientă că aventura sa ar putea să se 
termine într-un fel sau altul. De asemenea, Țara brînzei se prezintă (discret) ca o rescriere a celor două romane celebre, făcând și o posibilă aluzie la al treilea: The Foe al lui J. M. Coetzee, de care îl leagă personajul feminin, dar și încercările de a crea o poveste.

Imaginea robinsoniadei este susținută de faptul că satul este aproape pustiu, casa funcționează doar ca un adăpost temporar, iar relativ mult spațiu din ,jurnal” este ocupat de problemele necesităților fiziologice și de siguranță (nutriție, adăpost, igienă etc.).

La un moment dat, naratoarea comentează propria situație printr-o concluzie neașteptată: „Modelul Robinson nu-mi era de nici un folos. Eu nu puteam să organizez nimic din materia care mă înconjura, pentru simplul motiv că ea nu trebuia organizată, ci distrusă" (ȚB: 86). Astfel, în multe privințe romanul pare a fi (și) povestea unui anti-Robinson: este narat de o femeie; naufragiul ei este unul metaforic; exilul este autoimpus, singurul lucru care o împiedică să plece fiind propria încăpățânare; în ultimă instanță, „insula” nu este în acest caz un loc necunoscut și poate nici nu este un loc, ci o condiție sau un timp, iar toate eforturile ei nu sunt făcute în sensul evadării, ci dimpotrivă, au ca scop (după pură supraviețuire) o confruntare cu trecutul de care nu poate fugi.

\section{3. Țara brînzei - satul comunist și postcomunist}

Dan C. Mihăilescu (2005) vorbește despre Mihali în contextul realismului apocaliptic, accentuând viziunea pesimistă asupra lumii. Într-adevăr, stilul autoarei este direct, descrie realitatea într-un fel lipsit de iluzii: „Casele prăpădite, ulițele line de praf sau noroi, mirosurile și oamenii de acolo nu-mi lipseau. Alor mei nu le duceam dorul și vizita lor la București mă enerva" (ȚB: 15). Lumea copilăriei în care se întoarce deja din primele pagini pare a nu fi una agreabilă. Marcu (2002) vede miza acestui roman ca „,descompunerea umanității particulare care nu mai poate și nu mai vrea să lupte cu un mediu asasinat de sărăcie”, , acest mediu fiind în primul rând satul. După imaginea dezolantă a satului pustiit și părăginit, Mihali se oprește asupra ofertei sugestive de mărfuri de la magazin: „La unicul magazin existent se găseau de toate, de la pîine, macaroane, bulion, sodă, gaz, chibrituri, sare, ață, pînă la cizme de cauciuc, indispensabili, sape, cuie, linguri de aluminiu, găleți de tablă, ceas deșteptător, papuci de casă, pieptăn. Nu găseai însă nici cel mai amărît cap de creion sau ceva ce s-ar numi caiet ${ }^{2}$. Nu exista perie sau pastă de dinți, tifon, vată, otravă pentru șoareci și sprey pentru țînțari” (ȚB: 23).

Mihali descrie într-un interviu această localitate ca fiind „un sat românesc din mijlocul Bărăganului, jefuit de identitatea și de valorile lui de cei 50 de ani de comunism. Este o imagine care a lăsat neconsolați mulți nostalgici ai satului românesc, prizonieri ai filozofiei lui Blaga, aceea că veșnicia s-a născut la sat. Părerea mea e că dacă veșnicia s-a născut acolo, ar face bine să se mute în altă parte cât mai repede" (Halus 2018). Subliniază, deci, două lucruri: atitudinea

2 Motivul scrisului există în roman doar prin indicii, unul dintre ele fiind și acesta. 
ironică față de imaginea idilică a lumii rurale și problema moștenirii sumbre a sistemului comunist.

Satul românesc este pentru Felicia Mihali un loc sumbru despre care vorbește cu un cinism (Gheorghe 2010: 34, Ștefănescu 2007) care poate fi văzut și ca „un fel de durere de viață și defetism care ar fi consecința unor perioade istorice dificile" (Eiben 2007: 149). Ea distruge fără milă imagini stereotipice ale copilăriei și ale vieții la țară, satul nu mai este un loc sfânt și calm, valorile familiale nu mai sunt pe primul loc, casa părinților nu mai este un loc mitic unde seara se întâlnește toată familia (Eiben 2007: 150). Orice nostalgie este pusă sub semnul întrebării. Personajul principal „își amintește că 'raiul copilăriei' sale n-a însemnat altceva decât o existență prozaică, în mijlocul unei familii de oameni săraci și ignoranți, că tot ce-a urmat, la oraș, a fost la fel de dezamăgitor, că nimic din mitologia dragostei filiale, a școlii, a primelor experiențe erotice nu rezistă" (Ștefănescu 2009). Ironizarea și cinismul sunt pecetea romanului. Ironia îl vizează nu numai pe Blaga, deja menționat, ci și pe Creangă. Ion Creangă înfățișează chiar și râia căprească ca pe un amănunt amuzant al copilăriei idilice la țară și cititorului atent nu îi poate scăpa paralela cu alte infestări din lumea romanului. Comportamentul naratoarei față de puricii din casă sau față de furnicile de pe mâncare este destul de stoic, dar nu se transformă niciodată în nostalgie și nu are niciodată un ton ușor, umoristic, așa cum va fi, de exemplu, la Dan Lungu (Viața la țară. Viața la oraș. Paralela, 2003) sau la T. O. Bobe (Cum mi-am petrecut vacanța de vară, 2004).

Satul (post)comunist chiar și miroase urât. Naratoarea este foarte sensibilă la mirosuri, care îi rămân mereu vii în memorie și prin care percepe lumea exterioară: „Îmi trebuise extrem de puțin ca să mă vindec de infirmitatea simțului rege pentru mine, mirosul. Eram oarbă, surdă și mută. Dar știam să miros lumea. (...) Dacă trebuia să mă caut și să mă regăsesc, atunci trebuia să o fac exclusiv prin miros" (ȚB: 27). Descrierile olfactive demonstrează și un dezgust profund pentru mirosul și gustul brânzei, care este un reprezentant simbolic al satului și al copilăriei, un simbol al complexului originii: „Dacă aș fi acceptat de la început mirosul de brînză, totul ar fi fost altfel" (T,B: 32). Elena Francese (2008: 228) conchide argumentat că Țara brînzei este de fapt un roman sinestezic, o „reverie” senzorială. Accentul se pune în primul rând pe mirosurile dezagreabile, care urmăresc personajul pe tot parcursul romanului. Mirosul este, în general, un simț mai puțin dezvoltat la om, spre deosebire de animale, iar sensibilitatea personajului la mirosuri poate semnaliza întoarcerea la o viață rudimentară și primitivă (239-240). De asemenea, mirosurile sunt accentuate pentru a face cititorul conștient de căderea acestei femei, pentru care realitatea este distrusă împreună cu conexiunile logice (227). Exact invers decât în celebrul roman al lui Proust, unde madlena declanșează amintiri frumoase din copilărie, mirosul brânzei îi trezește naratoarei din Țara brînzei amintiri neplăcute dintr-o lume în care, refuzând de mică să mănânce brânză, a fost de la început percepută ca neadaptată: „Mama bănuia că sînt bolnavă, de vreme ce alimentul nostru de bază îmi facea rău" (ȚB: 57).

De-a lungul romanului, comunismul este omniprezent, fără să fie însă explicit menționat, dar și el poate fi descris cu ajutorul mirosurilor: „Transpirația lor [a bunicilor] nu era dizgrațioasă, duhnitoare. Transpirau ca sfinții. Trupul lor își 
autoconserva energia și mirosul. Cred că sudoarea acră apăruse odată cu CAPurile, cu transportul în remorci descoperite, cu femeile care purtau pantaloni pe sub fuste și căciuli sub batic, cu bărbații ce purtau ciorapii din supraelastic, în pantofii de vinilin, căciuli rusești cu urechi și beau alcool ieftin cu etanol" (ȚB: 37-38).

\section{Concluzii}

Romanul Feliciei Mihali poate fi citit și interpretat ca un discurs confesional (povestea naufragiului unui personaj care într-un fel pierde războiul cu complexul originii), dar și ca un roman social al decăderii satului. Deși romanul nu este autobiografic, ci doar marcat de o fază pesimistă a autoarei (Thibeault: 2002), luând în considerare polisemia cuvântului țară, precum și exilul autoarei care a urmat la un an după publicarea cărții, nu este lipsit de temei ca sintagma Țara brînzei să fie înțeleasă nu doar ca o metaforă a unui sat, ci și a întregii Românii din primii ani de după comunism.

\section{Bibliografie}

ȚB = Mihali, Felicia (1999). Țara brînzei, București: Editura Image.

Chartrand, Robert (2002). Une Robinsonne De Première Force, <http://www.feliciamihali.com/www/presse.html\#pays> (24/2/2019).

Chișu, Lucian (2016). Literary debates in the Romania's Nineties. Consequences and assessments, in Diversité et identité culturelle en Europe, 2/13, pp. 61-82.

Eiben, Ileana Neli (2007). La saison de la détresse et de la déchéance. Felicia Mihali et Marie-Claire Blais, écrivaines du malaise paysan, in Perspectives transculturelles sur le Canada, Vol. 7, pp. 149-157.

Francese, Elena (2008). Le pays du fromage de Felicia Mihali: Un roman synesthésique?, in: Gisèle Vanhese (ed.), Deux Migrants de L'écriture. Panaït istrati et Felicia Mihali, Rende: Centro editoriale e librario, pp. 227-246.

Gheorghe, Mircea (2010). Spre o nouă identitate, in Contemporanul, Vol. 4, pp. 34.

Halus, Eva (2018). Felicia Mihali: Romancierul cosmopolit, <http://accentmontreal. com/felicia-mihali-romancierul-cosmopolit/> (20/12/2018).

Iliceanu, Radu (2015). Prozatoarea Felicia Mihali, invitată la Biblioteca Franceză 'Omnia', <http://www.cvlpress.ro/16.07.2015/prozatoarea-felicia-mihali-invitatala-biblioteca-franceza-,,omnia/> (25/10/2018).

Manolescu, Nicolae (2008). Istoria critică a literaturii române. 5 secole de literatură, Piteşti: Editura Paralela 45, pp. 1398-1401.

Marcu, Luminița (2002). Felicia Mihali - Romanele scrise în România, România literară, 36, <http://www.romlit.ro/index.pl/felicia_mihali_-_romanele_ scrise_n_romnia> (15/10/2018).

Mihăilescu, Dan C. (2005). Jocuri de-a măcelul şi o iubire cît lumea. <https://atelier. liternet.ro/articol/2483/Dan-C-Mihailescu/Jocuri-de-a-macelul-si-o-iubire-citlumea.html> (20/11/2018). 
Ştefănescu, Alex. (1999). Reacții imediate: Un autor cinic, in România literară, 13, <http://www.romlit.ro/index.pl/un_autor_cinic> (15/12/2018).

Ştefănescu, Alex. (1999). Romanul unui personaj de roman, in România literară, 32, <http://www.romlit.ro/index.pl/prozatori_tineri> (15/10/2018).

Tanguay, Antoine (2002). La Naufragée au nez fin, <http://www.feliciamihali.com/ www/presse.html\#pays> (24/2/2019).

Thibeault, Pierre (2002). Dyna-Mythe, <http://www.feliciamihali.com/www/ presse.html\#pays>. (24/2/2019).

\section{Felicia Mihali's Confessional Prose}

Our research is focused on the novel Țara brînzei (1999) written by Felicia Mihali, a contemporary writer of Romanian origin. In 2000, the author emigrated to Canada and settled in Montreal, where she translated her own novel into French, publishing it under the title Le pays du fromage in 2002. Țara brînzei is her debut novel, which was well received in both countries. We approach the subject of this novel in the form of a confessional discourse, closely related to a personal diary.

Key words: Felicia Mihali, Romanian literature, self-translation, intertextuality 
